\title{
The Effect of Wage Subsidies on Piece Rate Workers: Evidence from the Penny Per Pound Program in
} Florida*

\author{
Hyejin $\mathrm{Ku}^{\dagger}$
}

March 2019

\begin{abstract}
This paper studies a fair trade program in which consumers provide a wage subsidy (bonus) to piece-rate tomato pickers. The total subsidy-determined by sales to participating buyers - is divided among workers based on their relative output: a worker who produces more gets a larger share of the bonus. Although seemingly mimicking the existing piece-rate pay scheme, the mechanism associated with the bonus payment is really a relative performance evaluation, as the size of total bonus is exogenous and invariant to workers' effort. Therefore, for a given sized subsidy, the combined total (or per worker average) utility gains would become the largest if the workers keep their efforts at the pre-program level. Empirical analysis shows that worker effort (and hence productivity) increases substantially in response to the program, suggesting that currently, workers' combined gains per dollar of subsidy are not being maximized.
\end{abstract}

Key words: piece rate, subsidy, fairness, tragedy of the commons, natural experiment JEL codes: J24, J31, J38, M52, O12

\footnotetext{
* I am very grateful to the family and staff at the study farm for their help and support for this project and to Julia Bonomo, Andres Chaves, Mark Flowers and Diana Saenz for their research assistance. I also thank the Editor (Jeremy Magruder), two anonymous referees, Jerome Adda, David Card, Steve Coate, Christian Dustmann, Hank Farber, Simon Gorlach, Ed Lazear, Magne Mogstad, Marco Ottaviani, Ian Preston, Imran Rasul, Dmitry Ryvkin, Uta Schoenberg and conference/workshop participants at Bergen, Cornell, Florida State, Frankfurt, NBER SI, SOLE/EALE, UBC, and UCL for helpful comments and suggestions.

${ }^{\dagger}$ Department of Economics, University College London, Gower Street, London, WC1E 6BT, UK; Email: h.ku@ucl.ac.uk.
} 


\section{Introduction}

Farm laborers in rural economies are among the lowest paid workers, and labor market policies and programs affecting agricultural workers have been at the center of development research (see, e.g. Stigliz 1974; Bardhan 1979; Rosenzweig 1988; Basu 2003). Due to their low income and harsh working conditions, farm workers are often subject to campaigns and initiatives that seek to subsidize their pay. A prominent example is the price premiums that some consumers in rich countries pay for "fair trade" products such as coffee, tea, cocoa, sugar and bananas. While participating consumers would hope that the premiums they pay will reach the farmers/laborers who grow and harvest those products, thereby improving their pay, empirical evaluation of wage subsidy's impact on agricultural workers is challenging for two main reasons. First, in most programs the financiers (i.e., consumers in rich countries) and target beneficiaries (i.e., agricultural workers in developing countries) are separated by complex layers of intermediaries in the supply chain (Chau et al. 2016; Mitra et al. 2018) and therefore the price premiums paid by consumers often dissipate before reaching the intended beneficiaries. Second, although agricultural workers - in particular harvesting workers - are often compensated by piece rate (see e.g., Bandiera et al. 2005; Kandilov and Vukina 2016; Guiteras and Jack 2018), hardly any existing surveys provide information on piece rate workers' earnings or other labor market outcomes (see Guiteras and Jack (2018) for a discussion).

This paper overcomes these challenges by studying a U.S-based fair trade initiative called the "Penny Per Pound" (PPP), a consumer-financed wage subsidy program targeted at piece-rate tomato pickers in Florida. For this program, participating buyers pay a one cent extra per pound of tomatoes purchased from Florida-based growers, which is then passed on to the workers who harvested the tomatoes. Here, thanks to the fact that both the financiers (i.e., participating buyers/consumers) and beneficiaries (i.e., tomato pickers) are located in the U.S. and the transfer scheme is strictly enforced, the price premiums paid by consumers indeed 
reached the workers in its entirety. This environment therefore allows us to evaluate the impact of wage subsidy on piece-rate agricultural workers in an "ideal" setting (i.e., where no leakage of funds takes place between financiers and beneficiaries), which should set a useful benchmark for understanding the subsidy's impact. Moreover, we use data from the personnel records of a large U.S. farm with rigorous record keeping standards, which provides a rare opportunity to examine, based on detailed micro-data, how consumer-financed subsidies might impact on the earnings and productivity of piece-rate workers in the field. The goal of this paper is therefore to understand the impact of this particular program on its target beneficiaries - the harvesting workers - and to think more generally about the effects of wage subsidies in piece-rate settings.

In evaluating the PPP policy, we focus on a common but largely overlooked issue regarding the distribution scheme to allocate the subsidy money among workers. In particular, the PPP program was administered so that the total subsidy — which is exogenously determined by sales to participating buyers in each week-is to be divided among workers based on their relative output in the relevant week: a worker who produces more buckets gets a larger share of the bonus. Since the total bonus available is exogenously determined (by the quantity purchased by participating buyers), a higher effort of every worker does not expand the total reward available but only leads to greater effort costs in aggregate. The combined total (or per worker average) utility gains for each dollar of transfer-an object that the consumerfinanciers of the PPP (or of other similar programs) presumably aim to maximize-would therefore become the largest if the workers can commit to keeping their efforts at the preprogram level. ${ }^{1}$ If the workers' post-program efforts deviate from their pre-program level, this

\footnotetext{
${ }^{1}$ To illustrate this point, imagine two identical workers. Both workers would be better off if both agree to exert their pre-program level of effort and simply split the bonus money in half. In a competitive equilibrium, however, each worker may try to increase his share on the fixed bonus and exert higher efforts than previously. While ending up with exactly the same amount of bonus as in the first situation (i.e., one half), in the second scenario both workers would have deviated from their initial effort choices - which were and still are optimal with respect
} 
would imply that the combined total (or per worker average) utility gains from the program fall below the maximum possible level.

The key empirical question then is whether and how the workers respond to the PPP program. Do they collude (and hence exert the pre-program effort level)? Or does each worker increase his/her efforts in an attempt to receive a larger share on the fixed sized total bonus, resulting in a "tragedy of the commons"? We examine this based on data collected at a large tomato farm ("ABC Farm" hereafter) in early 2010, during the pilot phase of the program and before the program's subsequent expansion to other farms across the state. ${ }^{2}$ To isolate workers' effort responses to the PPP program from other determinants of productivity (e.g., seasonality), we employ a difference-in-differences (DiD) strategy comparing worker productivity in two different varieties of tomatoes that are differentially exposed to the PPP program, in seasons with and without the PPP program, respectively (see Section 4 for details).

Overall, our empirical findings are consistent with workers increasing their efforts in response to the PPP bonus, which suggests that perfect collusion is not taking place in the setting examined here. Thus, in the current distribution scheme, it appears that the maximum possible gains - in terms of the combined total (or per worker average) utility gains - from a given sized PPP transfer are not being realized because of workers' positive effort responses.

Note that increasing worker productivity was never part of the PPP program's objective. Here, the effort responses arise because of the particular scheme adopted to distribute a fixed sized total subsidy to piece rate workers. While seemingly mimicking the existing piece-rate pay scheme in place, the mechanism used for the payment of PPP subsidy is really a relative

\footnotetext{
to the piece rate paid by the farmer/grower/employer, which remains constant throughout. We make this point more formally in Section 3, where we also allow for heterogeneous worker types.

${ }^{2}$ The piece rates paid by the ABC Farm remain constant throughout our study period, irrespective of the PPP program. The program was widely publicized end of 2010 when the Florida Tomato Growers Exchange - a trade association representing $90 \%$ of growers in the state-agreed to participate in the program, see, e.g., The New York Times (2010); The Wall Street Journal (2010). According to the Coalition of Immokalee Workers (CIW), the program in its full-fledged form was first implemented in November 2011.
} 
performance evaluation (Holmstrom 1982; Lazear and Rosen 1981), which—by inadvertently inducing worker effort responses — reduces the workers' combined total (or per worker average) utility gains from the program. ${ }^{3}$ If organizers of similar programs were to choose a scheme to distribute a fixed pot of subsidy money among piece rate workers, it is quite likely that they will settle on the same scheme as used here, since it seemingly emulates the piece-rate pay scheme in place. The implications of our analysis are thus likely to reach beyond the PPP program. In particular, our analysis highlights the importance of understanding the potential incentive effects of a policy design when considering subsidizing low-income, piece-rate workers who may be particularly responsive to changes in incentives.

Although our primary contribution is in evaluating the impact of a consumer-financed wage subsidy on piece-rate workers in an agricultural setting, this paper also adds to the growing body of empirical research in the literature that estimates worker effort responses to changes in pay schemes (Lazear 2000; Shearer 2004; Bandiera et al. 2005; Fehr and Goette 2007; Jayaraman et al. 2016; Friebel et al. 2017) or changes in piece rates offered within a piece rate regime (Paarsch and Shearer 1999; Haley 2003; Chang and Gross 2014; Stevens 2017; Guiteras and Jack 2018). Unlike in existing work in the literature, there is no explicit change in wage contracts between the employer (ABC Farm) and the workers. However, because of the way it was implemented, the PPP program alters the incentives facing workers from pure piece rate (paid by the $\mathrm{ABC}$ Farm) to piece rate (paid by the $\mathrm{ABC}$ Farm) plus a relative pay (with respect to the PPP bonus). Hence, it provides an interesting ground to test the degree of worker effort responses and collusion in the face of such implicit changes in incentives, which matters for the optimal incentive provision by firms (Prendergast 1999).

\footnotetext{
${ }^{3}$ This point can be related to the coordination problem theoretically analyzed in Dixit et al. (1997) in the context of lobbying groups and the government or to the problem of excessive entry empirically studied in Hsieh and Moretti (2003) in the context of real estate agents competing over fixed sized total commission.
} 
The remainder of the paper is organized as follows. Section 2 provides a background on the PPP program. In Section 3, we formalize the key argument of the paper. Section 4 presents the empirical analysis. Section 5 concludes the paper.

\section{Background}

The Penny Per Pound (PPP) program, also called the Fair Food Program, is the product of a long-standing campaign by the Coalition of Immokalee Workers (CIW) — a grassroot labor rights group based in Immokalee, Florida - to improve the pay and working conditions of farmworkers in Florida. ${ }^{4}$ A three-party agreement between the CIW, buyers (such as McDonald's and Burger King), and growers (farmers), it entails participating buyers paying a one cent extra per pound of tomatoes purchased from Florida-based growers, and the growers passing this fair trade premium on to the workers who harvested the tomatoes. Irrespective of the program, the growers continue to pay the going piece rates-e.g., $\$ 0.50$ for a 32-pound bucket of large round tomatoes - and the premium paid by consumers comes on top of the workers' regular pay. Although the program also emphasizes its non-pecuniary benefits such as improved labor rights and workplace protections, what forms its core is the penny per pound transfer from consumers to workers, which is the focus of this paper.

If all buyers participated in the program and paid the penny per pound premium, the program could be implemented as a straight increase in the piece rate (by 32 cents for every 32-pound bucket of tomatoes). In reality and in common with similar campaigns and initiatives driven by consumer activism (Basu and Zarghamee 2009; Harrison and Scorse 2010), not all buyers participate in the PPP program and the sales to participating (versus non-participating)

\footnotetext{
${ }^{4}$ For more information on the CIW and the Fair Food Program, see http://www.ciw-online.org/ and http://www.fairfoodprogram.org.
} 
buyers naturally fluctuate from week to week. ${ }^{5}$ Therefore, it is generally not possible to compute and announce to workers a "piece rate equivalence" of the PPP premiums for the relevant week-i.e., the relevant pay period-before the production takes place. Given this salient and practical issue, the program organizers decided that the total subsidy — which is exogenously determined by sales to participating buyers-shall be divided among workers based on their relative output in the relevant week: a worker who produces more buckets gets a larger share of the bonus.

\section{Conceptual Framework}

Using the simplest possible framework, we first explain the incentive structure at the farm prior to the introduction of the PPP. We then explain how the PPP program itself alters the incentive faced by workers. To be clear, our goal is not to question the optimality of the existing pay scheme or the optimality of the existing piece rates in use prior to the program. We simply take the pre-program situation as given and examine the changes brought about by the PPP program. To focus on the main issue studied in this paper-the inadvertent incentive effects induced by the PPP bonus in its current distribution scheme-we also abstract from other concerns such as uncertainty, asymmetric information, minimum wage, etc. ${ }^{6}$

\subsection{Status Quo}

There are $N(>1)$ workers in the field. The incentive scheme is pure piece rate such that the compensation for each worker is based on the known piece rate and his individual output

\footnotetext{
${ }^{5}$ Take the example of "fair trade" coffee, for instance. Some consumers are willing to pay a price premium for a fair trade coffee whereas other consumers are just fine with a regular coffee and do not pay the premium.

${ }^{6}$ How minimum wage affects worker efforts and productivity is a question of interest and importance. In the present context, the minimum wage remained stable around the introduction of the PPP, leaving little scope for interaction between minimum wage and the PPP program.
} 
alone. ${ }^{7}$ The piece rate, $p$, paid by the employer, remains constant throughout. Effort of level $E$ leads to output $q(E)=E$. Effort of level $E$ is associated with a cost of $C(E ; \theta)$, with $C_{E}>0$ and $C_{E E}>0$. When there is no risk of confusion, we will express $C_{E}$ and $C_{E E}$ simply as $C^{\prime}$ and $C^{\prime \prime}$, respectively. The parameter $\theta(>0)$ denotes the inverse of worker ability, such that $C_{\theta}>$ 0 and $C_{E \theta}>0$. We allow the ability parameter to differ across individuals so that if worker $j$ is of higher ability than worker $k$, then $\theta_{j}<\theta_{k}$.

Each worker $i$ chooses effort $E_{i}$ to maximize the payoff:

$$
V\left(E_{i} ; \theta_{i}\right) \equiv p E_{i}-C\left(E_{i} ; \theta_{i}\right)
$$

In a competitive equilibrium, each worker $i$ chooses effort level $E_{i}^{*}$ that satisfies

$$
p-C^{\prime}\left(E_{i}^{*} ; \theta_{i}\right)=0
$$

Notice that in the pre-program regime, workers' competitive choices of effort, $\left(E_{1}^{*}, \ldots, E_{N}^{*}\right)$ are also what would maximize their combined total utility, $\sum_{j}^{N} V\left(E_{j} ; \theta_{j}\right)$.

\subsection{With the PPP Subsidy in Place}

The farmer/grower/employer continues to pay the usual piece rate irrespective of the program. The PPP premium raised by sales to participating consumers is distributed to workers according to their relative output. Worker payoff in the bonus regime is therefore

$$
\underbrace{p E_{i}-C\left(E_{i} ; \theta_{i}\right)}_{V\left(E_{i} ; \theta_{i}\right)}+\underbrace{M \frac{E_{i}}{\sum_{j=1}^{N} E_{j}}}_{\text {PPP subsidy }},
$$

where $M>0$ is the total subsidy (bonus) available, exogenously determined by the quantity purchased by participating buyers.

\footnotetext{
${ }^{7}$ From here on, we use "he" or "his" to refer to a specific worker as in the context studied, most workers are in fact male, hence the male form reads more natural.
} 


\section{Competitive equilibrium}

In a competitive equilibrium, each worker $i$ chooses $E_{i}$, taking the choices of other workers as given. The effort choice in competition, $E_{i}^{* *}$, satisfies:

$$
p-C^{\prime}\left(E_{i}^{* *} ; \theta_{i}\right)+M \frac{\sum_{j \neq i} E_{j}^{* *}}{\left(\sum_{j} E_{j}^{* *}\right)^{2}}=0
$$

for all $i$ 's.

Result 1: In the subsidy regime $(M>0)$, each worker's competitive choice of effort is higher than his pre-program choice: $E_{i}^{* *}>E_{i}^{*}$ for all i's.

To see this point, re-write (3) as

$$
\left\{p+M \frac{\sum_{j \neq i} E_{j}^{* *}}{\left(\sum_{j} E_{j}^{* *}\right)^{2}}\right\}-C^{\prime}\left(E_{i}^{* *} ; \theta_{i}\right)=0
$$

and compare (1) with (4). In the former, the piece rate $p$ is compared against the marginal cost $C^{\prime}(\cdot)$ (where $E_{i}^{*}$ is at the intersection of a horizontal line $p$ and an upward-sloping curve $C^{\prime}(\cdot)$ ). In the latter, $p$ is augmented by $M \frac{\sum_{j \neq i} E_{j}^{* *}}{\left(\sum_{j} E_{j}^{*}\right)^{2}}$, which is positive for $M>0$ as long as $N>1$. Since $C^{\prime \prime}(\cdot)>0$, we can conjecture that $E_{i}^{* *}$ that satisfies (4) must be larger than $E_{i}^{*}$ that satisfies (1).

\section{Maximizing the combined total utility of all workers}

For a given subsidy or transfer $M$ they put on the table, the key objective of the program's financiers (i.e., participating buyers or consumers) would be to maximize the combined total (or per worker average) utility gains. ${ }^{8}$ To achieve that goal, a planner will choose $\left(E_{1}^{0}, \ldots, E_{N}^{0}\right)$ to maximize

\footnotetext{
${ }^{8}$ For the financiers of the PPP (or other similar programs), there is no reason why they would attach a larger preference weight on the wellbeing of a particular worker over another. Therefore, the total (or per worker average)
} 


$$
\begin{aligned}
& \sum_{j}^{N}\left\{p E_{j}-C\left(E_{j} ; \theta_{j}\right)+M \frac{E_{j}}{\sum_{k=1}^{N} E_{k}}\right\} \\
= & \sum_{j=1}^{N}\left\{p E_{j}-C\left(E_{j} ; \theta_{j}\right)\right\}+M,
\end{aligned}
$$

where $E_{i}^{0}$ satisfies

$$
p-C^{\prime}\left(E_{i}^{0} ; \theta_{i}\right)=0
$$

for all $i$ 's. From (1) and (6), we know that $E_{i}^{0}=E_{i}^{*}$, which is stated in Result 2 below.

Result 2: In the subsidy regime $(M>0)$, the effort level that maximizes the combined total utility of all workers coincides with their pre-program choice of effort: $E_{i}^{0}=E_{i}^{*}$ for all i's.

Result 3: In the subsidy regime $(M>0)$, the combined total utility realized in the competitive equilibrium, $\left(E_{1}^{* *}, \ldots, E_{N}^{* *}\right)$ is less than the maximum possible level, which is attainable if the workers adhere to their pre-program effort choices, $\left(E_{1}^{*}, \ldots, E_{N}^{*}\right)$.

By optimality of $\left(E_{1}^{0}, \ldots, E_{N}^{0}\right)$ in the planner's problem, (5), we know that

$$
\sum_{j=1}^{N}\left\{p E_{j}^{0}-C\left(E_{j}^{0} ; \theta_{j}\right)\right\}+M>\sum_{j=1}^{N}\left\{p E_{j}^{* *}-C\left(E_{j}^{* *} ; \theta_{j}\right)\right\}+M
$$

if $E_{i}^{* *} \neq E_{i}^{0}$ for at least some $i$ 's. However, from Result 1 we know that $E_{i}^{* *}>E_{i}^{0}$ for all $i$ 's. In addition, from Result 2, we also know that the planner's choices of effort $\left(E_{1}^{0}, \ldots, E_{N}^{0}\right)$ coincide with the workers' pre-program choices, $\left(E_{1}^{*}, \ldots, E_{N}^{*}\right)$. It therefore follows that

$$
\sum_{j=1}^{N}\left\{p E_{j}^{*}-C\left(E_{j}^{*} ; \theta_{j}\right)\right\}+M>\sum_{j=1}^{N}\left\{p E_{j}^{* *}-C\left(E_{j}^{* *} ; \theta_{j}\right)\right\}+M,
$$

utility gains achieved from each dollar of transfer seem to be a reasonable representation of the program's objective from an evaluation standpoint. 
as stated in Result 3. ${ }^{9}$

\section{Comments}

As pointed out by Holmstrom (1982), "competition among agents (due to relative evaluations) has merit soley as a device to extract information optimally" and "competition per se is worthless." ${ }^{10}$ In the current context, however, competition and extra efforts by individual workers do not generate any value to the principal (consumer-financiers of the PPP program). Unlike a straight increase in piece rate where everyone's higher effort brings higher rewards in aggregate, the total PPP bonus here is fixed by sales to participating buyers, which is exogenous to the effort choices of individual workers. Therefore, with respect to the PPP bonus, everyone's higher effort does not increase the total bonus available but only results in higher effort costs in aggregate.

Notice that if $N=1$ the condition (3) converges to condition (6). Hence, with a single worker, the problem of vacuous competition discussed above does not arise. To see the intuition, examine each worker's payoff function in the subsidy regime, provided in (2). As the second term shows, one worker's higher effort—while increasing the numerator and hence his share in the total bonus - increases the denominator for everyone (including himself), diluting the effect of everyone's effort. While each worker internalizes such dilution effect for himself, he does not internalize the externality/dilution effect he inflicts on other workers (see condition

\footnotetext{
${ }^{9}$ Note that although the post-PPP allocation with no effort response (A) achieves higher combined total (or per worker average) utility gains among all workers than the post-PPP allocation with positive effort response (B), individual utility gains in allocation A may not necessarily be higher than in allocation B for each and every worker. Throughout, however, our main discussion will be on the combined total (or per worker average) utility gains from each dollar of transfer received, as that criterion seems to best represent the program's objective unless the financiers of the program were to attach a larger preference weight on the gains of a particular worker over another.

${ }^{10}$ Gibbons and Murphy (1990) present a case where relative evaluation is indeed valuable. In particular, relative performance evaluation (RPE) is used in compensation and retention decisions affecting CEOs: the revision in a CEO's pay and the probability that a CEO remains in his position for the following year are positively and significantly related to firm performance, but are negatively and significantly related to industry and market performance. In this context, RPE allows the principal to extract useful information about the performance of different agents (individual CEOs), separating it from industry or market level common shocks.
} 
(3)). Therefore, when $N>1$, workers' competitive behavior leads to an equilibrium where their combined total utility is less than the maximum possible achievable (Result 3). In contrast, when $N=1$, the worker fully internalizes the externality/dilution effect that his effort inflicts on himself, hence the problem of vacuous competition is avoided.

The key empirical question then is whether and how workers respond to the PPP program. Any deviation from the pre-program level of effort will result in a total utility gain below the maximum possible level. We examine this below.

\section{Empirical Analysis}

\subsection{Setting and Data}

The primary data come from ABC Farm's payroll records and include detailed harvesting activities at the worker-field-variety levels for each day of three harvesting seasons spanning two years prior to the program (spring 2008 and 2009) and the first year of program implementation (spring 2010). Each harvesting season lasts for about two months depending on weather conditions and field lifecycle. This dataset also includes rudimentary demographic information on the harvesters, including their ages, genders, and hire dates. Parts of the analysis also use climatic data for the relevant harvesting periods taken from the Global Surface Summary of Day Data produced by the NOAA’s National Climatic Data Center. ${ }^{11}$

Our analysis focuses on the two core varieties of tomatoes that the ABC Farm grows: large round tomatoes, which are easy to pick, and small grape tomatoes, which take more time. ${ }^{12}$ The piece rate for a 32-pound bucket of round tomatoes, therefore, is 50 cents, whereas that for grape tomatoes is 3.75 dollars for the same sized bucket. These piece rates paid by the ABC Farm remain constant throughout irrespective of the PPP program. The sample includes

\footnotetext{
${ }^{11}$ https://www.ncdc.noaa.gov/.

${ }^{12}$ Although the farm grows more than two varieties, due to confidentiality agreement with the firm, this analysis is constrained to their two main varieties, round and grape, which represents over 70 percent of total man hours.
} 
all workers who harvested either round or grape tomatoes, during the three harvesting seasons (hereafter, Years 1, 2, and 3, respectively). To eliminate undue influence from outliers, we trim the production data at the top and bottom 2.5 percent of the year-variety specific productivity distribution.

In the field, the tomato bushes grow in tall thick rows. Once the field clock starts, the workers spread out across different rows and after completely picking one, move on to another and so on throughout the day. Individual workers are thus not attached to any particular row either within a day or during a season. Nor is there any team element involved in production: compensation is entirely based on piece rate and individual output measured in 32-pound buckets.

Figure 1 shows the pre-program characteristics of the two core crops. On average, each worker picks 22.29 buckets of round tomatoes per hour and 2.66 buckets of grape tomatoes. Clearly, it is much easier to fill up a 32-pound bucket with big tomatoes than with small tomatoes, and the piece rates $(\$ 0.50 /$ bucket versus $\$ 3.75 /$ bucket $)$ reflect such differences. In terms of earnings per hour (or in terms of shadow price of effort), therefore, the two varieties roughly equalize though not exactly. On average, a worker can make $\$ 11.14$ per hour on round and $\$ 9.97$ per hour on grape. ${ }^{13}$

Some background statistics are provided in Table 1. Panel A shows the production data at the transaction (i.e., worker-day-field-variety) level, separately for round and grape varieties. A transaction is the record of when the field clock for each worker starts to when it stops. ${ }^{14} \mathrm{~A}$ worker can have multiple transactions per day; e.g., a worker can work for 5 hours in the field, take a lunch break, and work for another 4 hours in the afternoon. On average, each transaction

\footnotetext{
${ }^{13}$ The fact that the hourly earnings from the two varieties are not exactly equalized in "levels" is not crucial for our empirical analysis. What is important is a parallel trend between the two varieties in the absence of the incentive changes induced by the PPP program.

${ }^{14}$ Each worker's output and work hours are rigorously kept track of in the field, based on a scanning device and an ID card (with a magnetic chip) attached to each worker's bucket.
} 
lasts for 4-5 hours. Naturally, productivity (pieces/hour) varies across years. For instance, average productivity (and hence earnings per hour) in both round and grape increased from Year 1 to Year 2, suggesting a favorable common shock in Year 2. From Year 2 to Year 3 (year of PPP program), average productivity in round increased whereas that in grape decreased.

Panel B shows worker-season level characteristics. There are 954, 1187 and 798 unique harvesters in Years 1,2 and 3, respectively. On each day, workers may be asked to pick either round or grape variety depending on the farm's harvesting requirement. During a given season, therefore, most workers pick both varieties, with the share of season total hours spent on round being around 50 percent. A typical harvester is about 29 years of age, male, and joined the farm in that season or the year before (tenure is computed as harvest year minus "hire year," the year when the worker registered with this farm for the first time).

Panel $\mathrm{C}$ shows the workforce size at the day-field-variety level. In Year 1, an average of 113 to 128 workers are harvesting the same variety in the same field. In the post-program period, the group size increased for both the round and grape varieties.

Beginning in Year 3, the PPP program was in place at the farm. For each pay period (one calendar week), each worker will get a share of the total PPP premium received from sales to participating buyers in that week, where the share is computed as the worker's weekly total buckets divided by the farm level total buckets across all varieties. ${ }^{15}$ The usual pay stub indicates tasks performed, total hours worked, pieces picked, piece rates, and earnings by date.

\footnotetext{
${ }^{15}$ According to the CIW, the PPP program was explained (in English and Spanish) to workers as follows: "The heart of the new Fair Food agreement is the wage increase for picking tomatoes, which is to be paid by tomato buyers. All participating buyers will pay one cent more per pound of tomatoes to the farmer. This money will be collected each week according to sales to these participating buyers. At the end of the week, the money from the additional cent that has been collected will be split among all of the pickers, based on each worker's production (Those who pick more buckets during the week receive a bigger raise). Since each person picks a different number of buckets each week, each person will receive a different amount of extra money every week from the additional cent. In short, it is like a bonus paid by the buyers directly to the pickers based on the total sales to participating buyers each week. The raise will appear each week in your regular check, but it will be on a separate line so that it can be identified clearly. All of this will make much more sense once it starts. If you still do not understand how the raise works after a few weeks, you can ask your supervisor, someone in the office, or you can call the CIW at *************,"
} 
Beginning in Year 3, a new line item called Fair Farming Practices was added that reported the bonus received from the PPP program.

Figure 2 plots the worker-weekly PPP bonus actually received against the predicted PPP bonus (computed based on the PPP distribution scheme above). Specifically, for each worker-week, the predicted PPP bonus is calculated as the worker's own buckets over farmlevel total buckets in that week, multiplied by the total PPP bonus received by all worker-weeks in the sample. The predicted and actual bonus appear well aligned (regression coef of 1.004 with SE of 0.00001), which is consistent with the fact that throughout program operation, a third-party auditor tightly monitored and ensured that the PPP premium was indeed passed on to its intended recipients (i.e., the harvesting workers).

Table 2 presents the magnitude of the PPP bonus that each worker received during the season in relation to his output and regular earnings. In Year 3, there were 798 unique workers. During the season, workers received, on average, $\$ 114$ in PPP bonus, which is about 8 percent of their regular earnings. Since each worker harvested, on average, 1902 buckets of tomatoes (across all varieties), the piece-rate equivalence would amount to $\$ 0.07 /$ bucket. Note that this piece-rate equivalence is what we computed ex post, based on the season-total PPP payment and season-total pieces harvested and the workers themselves would not have had this information during the season.

\subsection{Identifying the Incentive Effect of the PPP Program}

To identify the incentive effect of the PPP bonus, we compare workers' productivity in different varieties of tomatoes (round versus grape) between seasons with and without the program in place. The rationale for this identification strategy is that the PPP bonus was determined based solely on the relative volume each worker harvested regardless of variety, although there is a wide variation in the speed of harvesting the two types of tomatoes. Since 
the piece rate that each variety pays differs so widely $(\$ 0.50 /$ bucket for round and $\$ 3.75 /$ bucket for grape), the current distribution scheme renders the impact of the PPP bonus on grape almost negligible vis-à-vis that on round. ${ }^{16}$ This means that with respect to the PPP bonus, the relative incentive for round versus grape tomatoes increases whereas with respect to the piece rates paid by the $\mathrm{ABC}$ Farm, the relative incentive between round and grape remains constant throughout (since the piece rates paid by the $\mathrm{ABC}$ Farm remain constant irrespective of the PPP program).

In particular, we examine whether there is any disproportionate increase in the productivity of round tomatoes relative to grape tomatoes from the pre- to the post-program periods in a difference-in-differences (DiD) framework. This approach accounts for the baseline differences between the two varieties as well as any temporal variations between the pre and the post periods that commonly affect the productivity of the two varieties. We further allow for the possibility of the same observed weather conditions (temperature, precipitation, visibility, and wind speed) having differential effects on the productivity of the two varieties. Our identifying assumption is therefore that any pre to post changes other than the incentive changes induced by the PPP program and observed weather conditions will affect the productivity of the two varieties similarly.

The specific equation we estimate is:

$$
y_{i v f t}=\alpha_{t}+\beta T_{v}+\gamma\left(\text { Post }_{t} \times T_{v}\right)+\psi_{f}+\boldsymbol{Z}_{v f t} \delta+\left(\boldsymbol{C}_{\boldsymbol{t}} \times T_{v}\right) \lambda+\phi_{i}+u_{i v f t},
$$

where $y_{i v f t}$ is the $\log$ of productivity (pieces/hour) of worker $i$ for tomato variety $v$ in field $f$ on day $t, \alpha_{t}$ is the day fixed effect (which subsumes daily climatic conditions and farm-level daily common shocks), and $T_{v}$ is a dummy indicating whether variety $v$ is round tomatoes (versus grape tomatoes). The dummy variable Post $_{t}$ indicates whether day $t$ is in the post-PPP

\footnotetext{
${ }^{16}$ For instance, a PPP bonus (in piece rate equivalence) of $\$ 0.07 /$ bucket translates into a 14 percent increase in piece rate for round and a mere 1.8 percent increase for grape. More generally, for any non-zero amount of PPP bonus, the percentage increase in piece rate for round is $7.5(3.75 / 0.50)$ times as large as that for grape.
} 
period (i.e., Year 3), the level effect of which is subsumed in the day fixed effects $\alpha_{t}$, and $\psi_{f}$ are field fixed effects. The coefficient of interest is $\gamma$, capturing the disproportionate change in productivity in round relative to grape post program.

The vector $\boldsymbol{Z}_{v f t}$ includes a cubic of the variety-specific field lifecycle $\left(L C_{v f t}\right)$, which is to account for the density of the crops available for picking may differ between days, ${ }^{17}$ and supervisor fixed effects (as in Lazear et al. 2015). Standard errors are clustered at the day level. ${ }^{18}$ We also allow for the possibility for the same climatic conditions having differential effects on the two varieties by including $\boldsymbol{C}_{\boldsymbol{t}} \times T_{v}$, where $T_{v}$ again indicates round (versus grape) variety and $\boldsymbol{C}_{\boldsymbol{t}}$ includes average temperature, precipitation, visibility and wind speed on each day. ${ }^{19}$ It should be noted that the level effect of $\boldsymbol{C}_{\boldsymbol{t}}$ is subsumed in the day fixed effects $\alpha_{t}$, meaning that the effect of any common shocks affecting the productivity of both varieties similarly-e.g., possible morale boost or non-pecuniary benefits associated with the PPP program - is already accounted for. In some specifications, we also include worker fixed effects $\phi_{i}$, comparing the same worker's productivity between the two varieties and across seasons.

\subsection{Results}

\section{$\underline{4.3 .1 \text { Overview }}$}

A first visual illustration of productivity changes in the post period is given by Figure 3 . The figure shows, for each variety, the kernel density estimates of the season-average productivity by workers during the periods with and without the program. For each worker, season-average productivity is computed as his season total output (pieces) divided by his season total field

\footnotetext{
${ }^{17}$ Following Bandiera et al. (2005), we measure $L C_{v f t}$ as the number of calendar days the field has been picked for that variety at any moment in time divided by the total number of days the variety was picked in that field over the season.

${ }^{18}$ Our main results are robust to two-way clustering (Cameron et al. 2011) at the day and worker levels, which are by far the most important dimensions of heterogeneity in our context.

${ }^{19}$ See Stevens (2017) for evidence on the sensitivity of worker efforts to temperature.
} 
hours worked. Panel (a) shows the productivity distribution for round and panel (b) for grape. With the PPP program in place, the distribution of worker productivity for round tomatoes shifts to the right, whereas that for grape tomatoes remains virtually the same.

In Table 3, we present a series of regressions comparing the simple difference in worker productivity before and after the PPP, separately for round and grape tomatoes. The results for round are in Columns 1 through 5 and those for grape in Columns 6 through 10. Column 1 shows the baseline regression, controlling for field fixed effects only. It shows that with the PPP in place, the productivity in round went up by $0.181 \log$ points or 19.8 percent. Column 2 includes a cubic of the following climatic variables: average temperature, precipitation, visibility, and wind speed. The number of observations drops slightly due to missing climatic data for some dates. The coefficient on Post goes up to 0.223. Column 3 includes a cubic of variety-field specific lifecycle (LC). Column 4 includes supervisor fixed effects. Lastly, column 5 includes worker fixed effects. The coefficient on Post remains positive and highly significant. Columns 6 through 10 show the same regressions for grape. In the case of grape tomatoes, worker productivity, if anything, went down slightly in the season with the PPP in place although none of the coefficients are statistically significantly different from zero.

Overall, the results in Table 3 indicate a significant increase in productivity (arguably effort driven) in round tomatoes post program, whereas no such increase is found in grape tomatoes. Although these results are obtained after controlling for an extensive list of field, climate and worker characteristics that may co-vary with the Post dummy, there still can be unobservable factors that affect productivity yet are not accounted for. To better isolate the PPP's incentive effect from such omitted covariates of the Post $t_{t}$ dummy, we next turn to our DiD estimates. 


\subsubsection{Difference-in-differences estimates}

Table 4 presents the estimates of equation (7). According to the estimate in column 1, relative to grape tomatoes (the reference variety), the productivity in round tomatoes increased disproportionately in the post-program period. The point estimate suggests that hourly productivity for round relative to grape increased by $0.277 \log$ points. ${ }^{20}$ Column 2 also controls for day fixed effects, which accounts for the effects of climatic and other unobserved changes across days that may affect productivity. In column 3, we control for a cubic of field lifecycle. Column 4 controls for supervisor fixed effects. Column 5 also controls for worker fixed effects, essentially comparing within-worker productivity differences in round versus grape between the pre and the post-program seasons. The estimate in column 5 hardly differs from that in column 4, suggesting that the positive effects found are not driven by compositional changes in the workforce between the pre and the post-program seasons.

\subsubsection{Robustness checks}

Differential effects of climate conditions on round and grape. The results reported in Table 4 above already account for - through inclusion of day fixed effects - the common effects of daily weather (and other unobservable) fluctuations on the productivity of the two varieties. However, it is possible that the same climatic conditions may have differential effects on the round versus grape tomatoes. Therefore, in Table 5, we include the interaction of a list of climatic variables we observe and the round dummy. As shown, the DiD coefficients are robust to the inclusion of the extra controls, meaning that our baseline results are unlikely to be driven by the same weather conditions differentially influencing the productivity of the two varieties.

\footnotetext{
${ }^{20}$ Note that the DiD strategy allows for the identification of the incentive effect in relative terms only (round versus grape), and here we do not make any causal interpretation about productivity changes in the reference variety, namely grape.
} 
This also serves as one test of the parallel trend assumption underlying our identification strategy, albeit with respect to observed climatic conditions only.

Placebo treatment. Table 6 reports the results of placebo tests, examining whether the disproportional productivity change in round is indeed due to the PPP program rather than representing a secular trend that may differ by variety. Column 1 shows the results for the preferred specification (presented in Table 4, column 4) with Post $\times$ Round replaced by Year $2 \times$ Round and Year $3 \times$ Round (with year 1 as the reference). As expected, there is no differential productivity response between the two varieties in Year 2; a positive effect is present only in Year 3 (the post-PPP season). In columns 2 and 3, we use Year 1 as the base year to check for any disproportionate productivity increase in round tomatoes in Years 2 and 3, respectively. Clearly, there is no effect in Year 2, but the positive effect for Year 3 is still present. This effect continues to hold when we use data from Years 2 and 3 only with Year 2 as the base year (column 4). Columns 5 through 8 further include worker fixed effects to keep the composition of workers constant across the years compared. Overall, the results are more consistent with the specific effect of the PPP program rather than a secular trend that may be present in any year irrespective of the PPP.

Assignment to crop varieties. As we saw in panel B of Table 1, the share of season total field hours spent on round is around 50 percent on average, meaning that most workers pick both round and grape varieties during a given season. Since the share of hours spent on round varies across individuals, we examine whether that share may be systematically related to their productivity. As Figure 4 shows, however, workers' share of field hours spent on round seems orthogonal to their productivity, where each worker's productivity is proxied by worker FE (see Mas and Moretti (2009)). Specifically, we estimate the worker FE by regressing worker- 
day-field-variety level log productivity (pieces/hour) on worker FE while conditioning on day FE, field FE, variety FE, a cubic of field-variety lifecycle, and supervisor FE. The pattern in Figure 4 suggests that the increased productivity in round is unlikely to be driven by the sorting of higher productivity workers into the round variety.

Possible adjustment in workforce size. Given that collusion is more difficult in a larger group (Isaac et al. 1988), we next examine whether the workforce size may have increased disproportionately for the round variety in the post period. In Table 7, where we regress the (log of) number of workers present for each variety-field-day on the interaction of Post and Round, we find no evidence of disproportional increase in workforce size for round variety relative to that for grape in the post period. Relatedly, controlling for workforce size (either in level or $\log$ ) in equation (7) does not alter our main DiD estimates, which is to be expected given the orthogonality of the workforce size to the treatment of interest Post $\times$ Round as shown here.

Labor supply. So far our discussion has focused on the effort, or work intensity. In principle, the variable $E_{i}$ in our theoretical framework (Section 3) can be viewed as hours worked, how hard one works during a given hour, or a combination of the two (Lazear 1986). In the case of cab drivers (Farber 2005, 2015) or stadium vendors (Oettinger 1999), the primary margin of response is how many hours workers work per day. ${ }^{21}$ In contrast, workers in our contextsimilar to the fruit packers in Chang and Gross (2014)— - have little choice over hours worked because conditional on working that day, all workers arrive when the harvesting starts in the morning and stay (and harvest) in the field until the day's harvesting is completed. Therefore,

\footnotetext{
${ }^{21}$ For instance, on a rainy day, when the customer traffic/demand conditions are favorable (in terms of hourly earnings), taxi drivers can choose to go home early. There, "how hard" the driver works per hour is less important.
} 
the key margin of adjustment available for workers here is effort, or work intensity, rather than hours worked.

Figure 5 illustrates this idea. Consistent with the daily operation of the farm described above, there is a strong positive correlation between the mean hours workers spend (vertical axis) and the "field capacity" proxied by the total output harvested at the day-field level divided by the number of workers assigned to that day-field (horizontal axis). ${ }^{22}$ That is, when there is more crops to harvest per worker, workers on average stay longer in the field. We then examine in Table 8 whether/how the field hours of individual workers may respond to the PPP program, in a DiD framework similar to equation 7. Column 1 shows, consistent with Figure 5, that field capacity is an important driver of field hours spent. Column 2 allows the correlation between field hours and capacity to differ by variety. Column 3 shows that field hours spent on round decreased by $0.253 \log$ points in the post program season relative to grape. But notice that the absolute magnitude is roughly the same as the effort response that we estimated in Table $4 .{ }^{23}$ That means there is no "extra" labor supply response beyond the mechanical drop in hours due to the effort responses we have focused on so far. The coefficient on Post $\times$ Round remains stable when we additionally control for (log) workforce size (column 4). Overall, this is the best evidence we can provide in terms of hours worked in this context, and it seems to be consistent with the observation that hours worked are not really the workers' choice variable whereas effort or work intensity is.

\footnotetext{
${ }^{22}$ Ideally, we would like to use the total number of ripe tomatoes available in a given field to approximate field capacity but that information is unobservable, hence we use the total output actually harvested here.

Nonetheless we use the phrase "field capacity" in this section purely for ease of exposition.

${ }^{23}$ For instance, the coefficient in 0.399 (SE: 0.078 ) in column 4 of Table 4 is not statistically significantly different from 0.253 (SE: 0.062).
} 


\subsection{Interpretation and Comments}

Overall, the DiD analysis corroborates that the observed productivity increase in round post program (Table 3) is likely driven by worker effort response to the changed incentive induced by the PPP bonus. To put the magnitude of these productivity responses in context, we can draw on the existing literature that looks at productivity elasticities to piece rates. For instance, Paarsch and Shearer (1999) estimate, among piece rate tree planters in British Columbia, the elasticity of productivity with respect to the piece rate to range from 0.77 to 2.14 . In a similar study by Haley (2003), the figure ranges between 0.41 and 1.51 . Among casual laborers sorting beans in Malawi, Guiteras and Jack (2018) obtain an elasticity of 0.06 (conditional on the individual's reservation piece rate). Based on our estimates and depending on the assumptions we make, we get an upper bound of 1.35 to 2.21 and a lower bound of 0.29 to $0.48 .{ }^{24}$ Of course, these should be taken cautiously as there are peculiarities about the PPP program that make it difficult to generalize these findings to traditional piece rate settings. Also we see no response for grape tomatoes.

An interesting question that arises, given prior research that finds evidence of collusion and social preferences among agricultural workers (Bandiera et al. 2005), is why the tomato pickers studied here responded the way they did when no increase in productivity (i.e., full collusion) would have been the collectively optimal response to the PPP. The present setting is at variance with that in Bandiera et al. (2005) in several ways. First of all, Bandiera et al. (2005)

\footnotetext{
${ }^{24}$ Based on the different methods, the conservative estimate of productivity change in round is 0.181 to $0.277 \log$ points (or 19 to 31 percent). To see the implied elasticity from these figures, consider the magnitude of the PPP bonus reported in Table 2 . The piece-rate equivalence in the PPP was about $\$ 0.07 /$ bucket, which is roughly 14 percent $(0.07 / 0.50)$ increase in the effective piece rate for round. As mentioned above, this piece-rate equivalence is what we computed ex post, based on the season-total PPP payment and season-total pieces harvested and the workers themselves would not have had this information during the season. Therefore, the implied elasticity of productivity (in round) with respect to the piece rate is between 1.35 and 2.21. This can be thought of as an upper bound of the elasticity as it is based on the actual PPP received (\$0.07/bucket) that is computed ex post whereas the workers' perceived magnitude of the PPP payment may have been larger than that. For instance, had the workers reacted to the PPP program, thinking that the program coverage would be 100 percent with a PPP subsidy of $\$ 0.32 /$ bucket (or 64 percent increase in the effective piece rate for round, $0.32 / 0.50$ ), the implied elasticity would be between 0.29 to 0.48 , which serves as the lower bound of the implied elasticity.
} 
compare worker productivity under two explicitly different compensation schemes, namely relative pay (pre) versus piece rate (post). In the present study, however, the regime shift under consideration is from pure piece rate (pre) to a combination of piece rate and relative pay (post): in the post period, the $\mathrm{ABC}$ farm continues to pay the existing piece rate, whereas the relative pay is used with respect to the payment of PPP only. Due to this hybrid nature of the incentive schemes in the post period, achieving full collusion exclusively with respect to the PPP bonus may have been more difficult.

Second, the work environment of the tomato pickers may not be conducive to (full) collusion. At the $\mathrm{ABC}$ farm, the number of workers in a given field is quite large, typically over 100, a group size substantially higher than what facilitates cooperation (Isaac et al. 1988). Moreover, tomato bushes are quite thick and tall and that precludes both active monitoring and mutual enforcement of collusion among workers (cf. Bandiera et al. 2005 and 2010). Both these circumstances may have precluded full collusion among workers with respect to the PPP bonus.

\section{Conclusion}

This paper examines the impact of the Penny Per Pound (PPP) program in which consumers provided a wage subsidy (bonus) to piece rate tomato pickers in Florida farms. Thanks to its intuitiveness and simplicity, "one penny more per pound (of tomatoes picked)" worked as a powerful campaign to attract the attention of well-meaning consumers. In practice, however, it was not possible to implement the program as a straight increase in piece rate because of the fact that only sales to participating (versus non-participating) buyers would generate the penny per pound premium. In response to this common and practical issue, the program organizers decided to divide the total subsidy among workers based on their relative output. While seemingly mimicking a piece rate pay_-workers who pick more get a larger bonus - the total bonus here is exogenously determined by sales to participating buyers. Therefore, unlike a 
straight increase in piece rate where everyone's higher effort brings higher rewards in aggregate, everyone's higher effort does not increase the total bonus available but only results in higher effort costs in aggregate, which makes the combined total (or per worker average) utility gains from the program to become smaller than the maximum possible. Given the prevalence of piece rate pay among agricultural workers (Bandiera et al. 2005; Kandilov and Vukina 2016; Stevens 2017; Guiteras and Jack 2018), the issue we point out here may arise in other contexts if workers are subject to similar campaigns and initiatives to subsidize their pay. More broadly, our analysis highlights the importance of understanding the potential incentive effects of a policy design when considering subsidizing low-income agricultural workers.

\section{References}

Bandiera, Oriana, Iwan Barankay, and Imran Rasul, 2005. "Social Preferences and the Response to Incentives: Evidence from Personnel Data," Quarterly Journal of Economics, 120(3): 917-962.

Bandiera, Oriana, Iwan Barankay, and Imran Rasul, 2010. "Social Incentives in the Workplace," Review of Economic Studies, 77(2): 417-458.

Bardhan, Pranab K., 1979. "Labor Supply Functions in a Poor Agrarian Economy,” American Economic Review, 69(1): 73-83.

Basu, Kaushik, 2003. Analytical Development Economics: The Less Developed Economy Revisited, MIT press.

Basu, Kaushik, and Homa Zarghamee, 2009. "Is Product Boycott a Good Idea for Controlling Child Labor? A Theoretical Investigation," Journal of Development Economics, 88(2): 217-220. 
Cameron, A. Colin, Jonah B. Gelbach, and Douglas L. Miller, 2011. "Robust Inference with Multiway Clustering," Journal of Business \& Economic Statistics, 29(2): 238-249.

Chang, Tom, and Tal Gross, 2014. "How Many Pears Would a Pear Packer Pack if a Pear Packer Could Pack Pears at Quasi-exogenously Varying Piece Rates?,” Journal of Economic Behavior \& Organization, 99: 1-17.

Chau, Nancy H., Hideaki Goto, and Ravi Kanbur 2016. "Middlemen, Fair Traders, and Poverty," Journal of Economic Inequality, 14(1): 81-108.

Dixit, Avinash, Gene M. Grossman, and Elhanan Helpman, 1997. "Common Agency and Coordination: General Theory and Application to Government Policy Making," Journal of Political Economy, 105(4): 752-769.

Farber, Henry S., 2005. "Is Tomorrow Another Day? The Labor Supply of New York City Cabdrivers," Journal of Political Economy, 113(1): 46-82.

Farber, Henry S., 2015. "Why You Can't Find a Taxi in the Rain and Other Labor Supply Lessons from Cab Drivers," Quarterly Journal of Economics, 130(4): 1975-2026.

Fehr, Ernst and Lorenz Goette, 2007. "Do Workers Work More If Wages Are High? Evidence from a Randomized Field Experiment,” American Economic Review, 97(1): 298-317.

Friebel, Guido, Matthias Heinz, Miriam Krüger, and Nick Zubanov, 2017. “Team Incentives and Performance: Evidence from a Retail Chain," American Economic Review, forthcoming.

Gibbons, Robert, and Kevin J. Murphy, 1990. "Relative Performance Evaluation for Chief Executive Officers," ILR Review, 43(3): 30-S.

Guiteras, Raymond P., and B. Kelsey Jack, 2018. "Productivity in Piece-rate Labor Markets: Evidence from Rural Malawi," Journal of Development Economics, 131: 42-61. 
Haley, M. Ryan, 2003. "The Response of Worker Effort to Piece Rates: Evidence from the Midwest Logging Industry,” Journal of Human Resources, 38(4): 881-890.

Harrison, Ann, and Jason Scorse, 2010. "Multinationals and Anti-sweatshop Activism," American Economic Review, 100(1): 247-273.

Holmstrom, Bengt, 1982. "Moral Hazard in Teams," The Bell Journal of Economics, 1982: 324-340.

Hsieh, Chang-Tai, and Enrico Moretti, 2003. "Can Free Entry Be Inefficient? Fixed Commissions and Social Waste in the Real Estate Industry," Journal of Political Economy, 111(5): 1076-1122.

Isaac, R.M. and Walker, J.M., 1988. "Group Size Effects in Public Goods Provision: The Voluntary Contributions Mechanism," Quarterly Journal of Economics, 179-199.

Jayaraman, Rajshri, Debraj Ray, and Francis de Vericourt, 2016. "Anatomy of a Contract Change," American Economic Review, 106(2): 316-358.

Kandilov, Ivan and Tomislav Vukina, 2016. "Salaries or Piece Rates: On the Endogenous Matching of Harvest Workers and Crops," Economic Inquiry, 54(1): 76-99.

Lazear, Edward P., 1986. "Salaries and Piece Rates,” Journal of Business, 405-431.

Lazear, Edward P., 2000. "Performance Pay and Productivity," American Economic Review, 90(5): 1346-1361.

Lazear, Edward P. and Sherwin Rosen, 1981. "Rank-Order Tournaments as Optimum Labor Contracts," Journal of Political Economy, 89(5): 841-864.

Lazear, Edward P., Kathryn L. Shaw, and Christopher T. Stanton, 2015. “The Value of Bosses,” Journal of Labor Economics, 33(4): 823-861. 
Mas, Alexandre, and Enrico Moretti, 2009. "Peers at Work," American Economic Review, 99(1): 112-45.

Mitra, Sandip, Dilip Mookherjee, Maximo Torero, and Sujata Visaria, 2018. "Asymmetric Information and Middleman Margins: An Experiment with Indian Potato Farmers," Review of Economics and Statistics, 100(1): 1-13.

“One Penny More a Pound,” Editorial, New York Times, December 3, 2010.

Oettinger, Gerald S., 1999. "An Empirical Analysis of the Daily Labor Supply of Stadium Vendors," Journal of political Economy, 107(2): 360-392.

Paarsch, Harry J. and Bruce S. Shearer, 1999. "The Response of Worker Effort to Piece Rates: Evidence from the British Columbia Tree-Planting Industry," Journal of Human Resources, 34(5): 643-667.

Perez, Evan, “Major Grower to Join Wage Plan,” Wall Street Journal, October 13, 2010.

Prendergast, Canice, 1999. "The Provision of Incentives in Firms," Journal of Economic Literature, 37(1): 7-63.

Rosenzweig, Mark R. 1988. "Labor Markets in Low-income Countries," Handbook of Development Economics, vol. 1: 713-762.

Shearer, Bruce, 2004. "Piece Rates, Fixed Wages and Incentives: Evidence from a Field Experiment," Review of Economic Studies, 71(1): 513-534.

Stevens, Andrew, 2017. “Temperature, Wages, and Agricultural Labor Productivity,” working paper, Mississippi State University.

Stiglitz, Joseph E., 1974. “Alternative Theories of Wage Determination and Unemployment in LDC's: The Labor Turnover Model," Quarterly Journal of Economics, 88(2): 194-227. 
Figure 1: Piece rates, pieces, and earnings

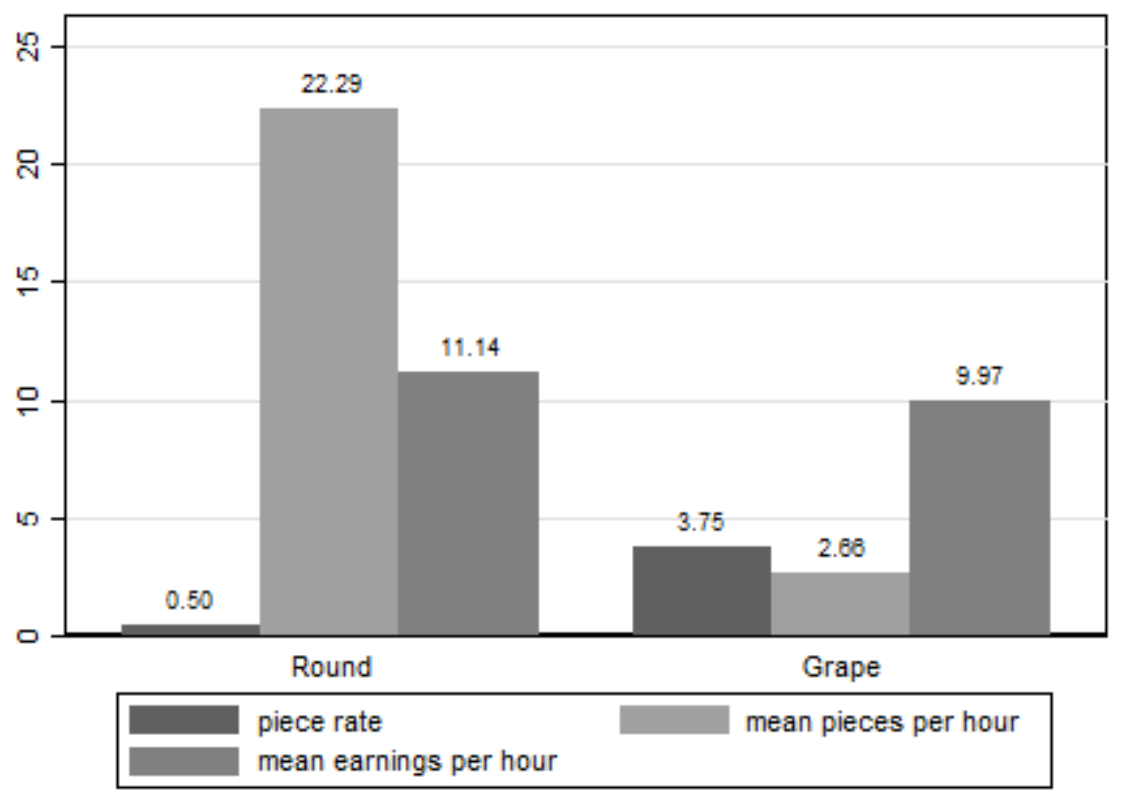

Based on preprogram (Years 1 and 2) data only. Output is measured in 32-pound buckets. The piece rates remain constant throughout at \$0.50/bucket for Round and \$3.75/bucket for Grape, respectively. The mean pieces per hour and mean earnings per hour shown are an average across all workers present, where for each worker-year, the season average productivity (pieces/hour) is computed as her season total output (pieces) divided by her season total hours worked. Similarly, each worker's season average earnings per hour are computed as her season total earnings divided by her season total hours worked. 
Figure 2: Predicted versus actual PPP payment

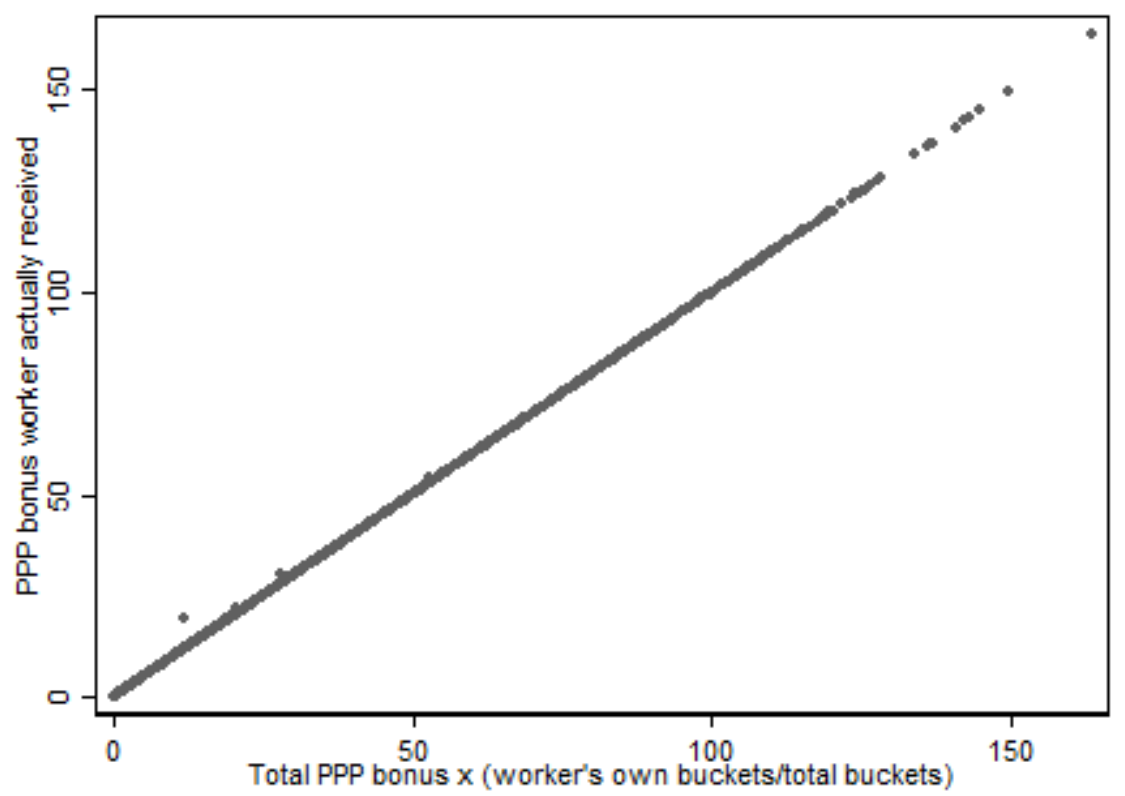

Based on data from the postprogram season (Year 3). This figure plots the worker-weekly PPP bonus actually received against the predicted PPP bonus. For each worker-week, the predicted PPP bonus is calculated as the worker's own buckets over farm-level total buckets in that week, multiplied by the total PPP bonus received by all worker-weeks in the sample. The predicted and actual bonus amounts appear well aligned (regression coef of 1.004 with SE of 0.00001). 
Figure 3: Distribution of worker productivity in the pre versus postprogram periods

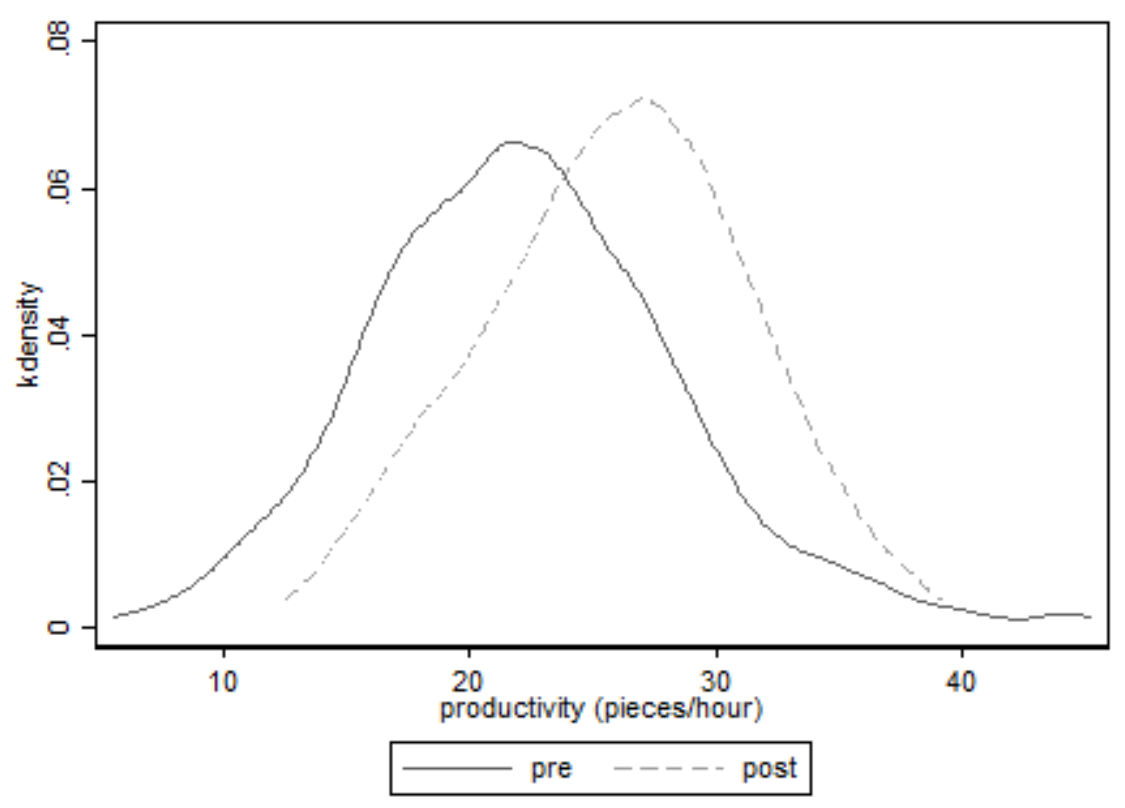

(a) Round

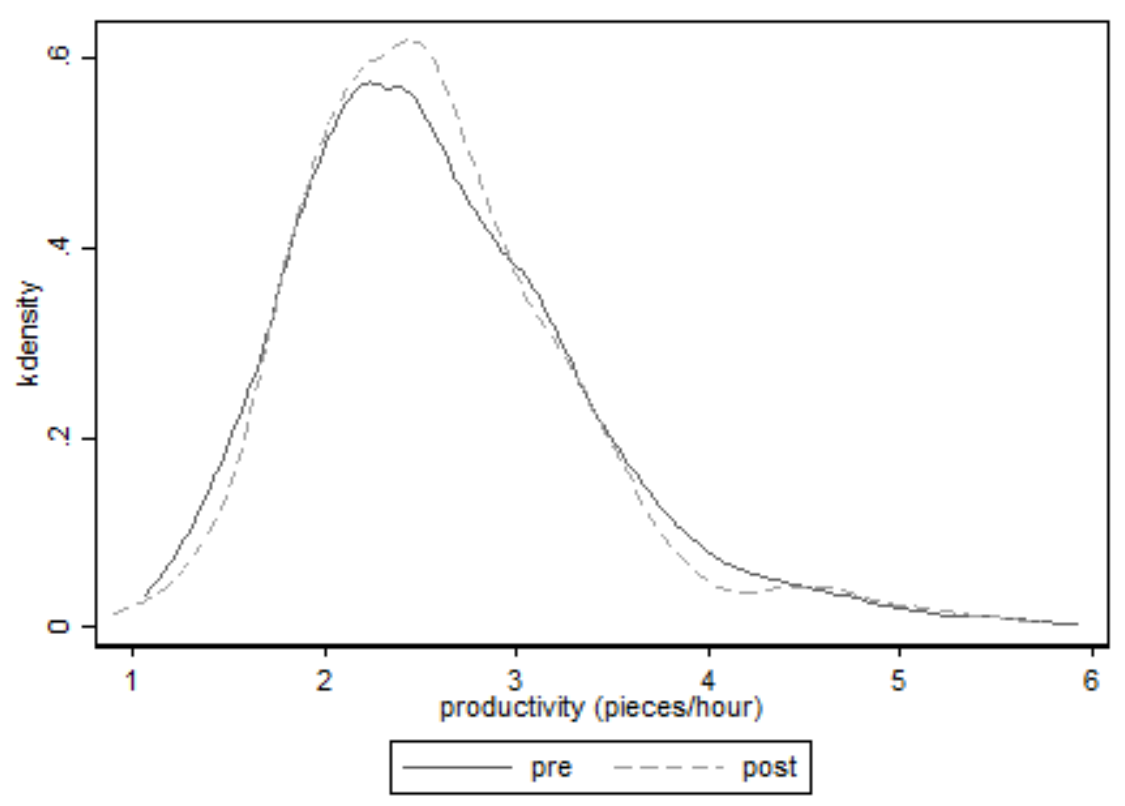

(b) Grape

The kernel density estimates of season average productivity by workers are plotted for the pre (solid line) and post (dashed line) program periods. For each worker-year, the season average productivity (pieces/hour) is obtained from dividing her season total output (pieces) by her season total hours worked. Panel (a) shows the productivity distribution for round and panel (b) for grape. Based on 2,627 workeryear level observations for panel (a) and 2,733 for panel (b). 
Figure 4: Share of field hours spent on the round variety by worker productivity

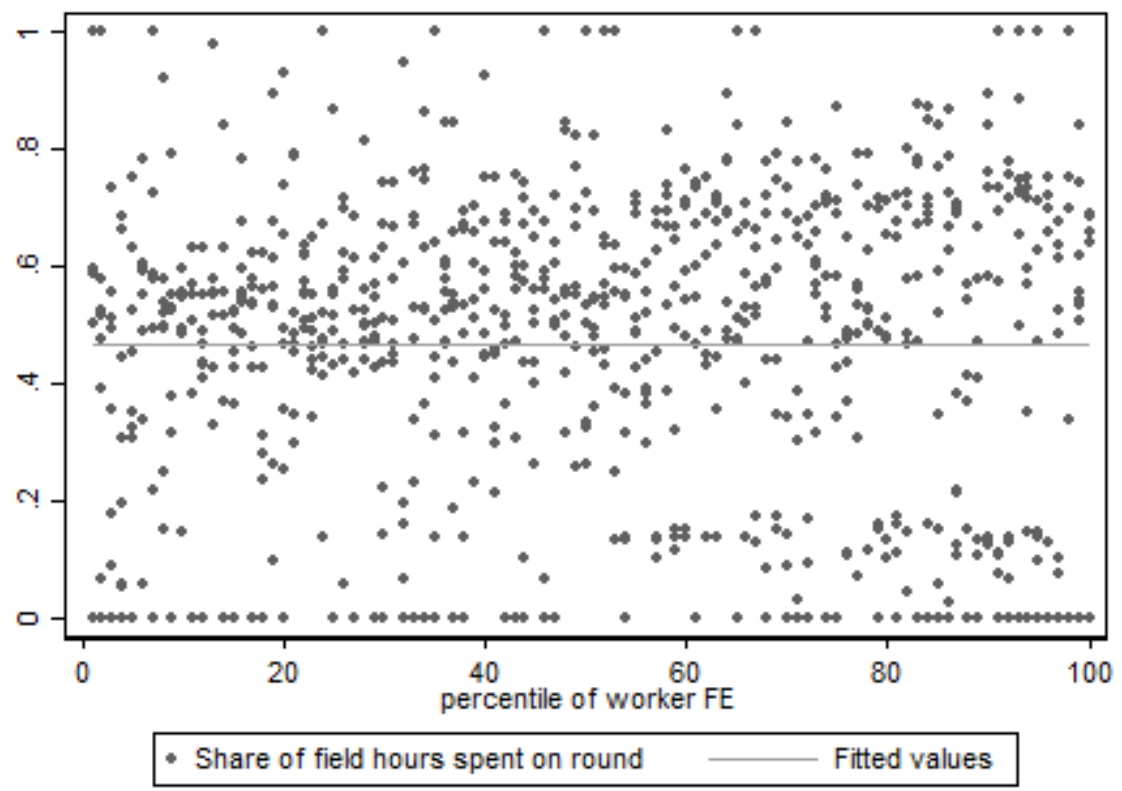

Based on data from the postprogram season (Year 3). This figure plots the share of field hours that each worker spent on round (vs. grape) variety against her productivity (proxied by worker FE). Vertical axis shows the share of total field hours that each worker spent on round during the season. Horizontal axis shows the percentile of worker FE. Worker FE is estimated by regressing worker-day-field-variety level $\log$ productivity (pieces/hour) on worker FE while conditioning on day FE, field FE, variety FE, a cubic of field-variety lifecycle, and supervisor FE. A total of 798 workers are represented in the figure. The coefficient of the regression line is -.0000181 with standard errors .0003441 . 
Figure 5: Field hours worked by field capacity

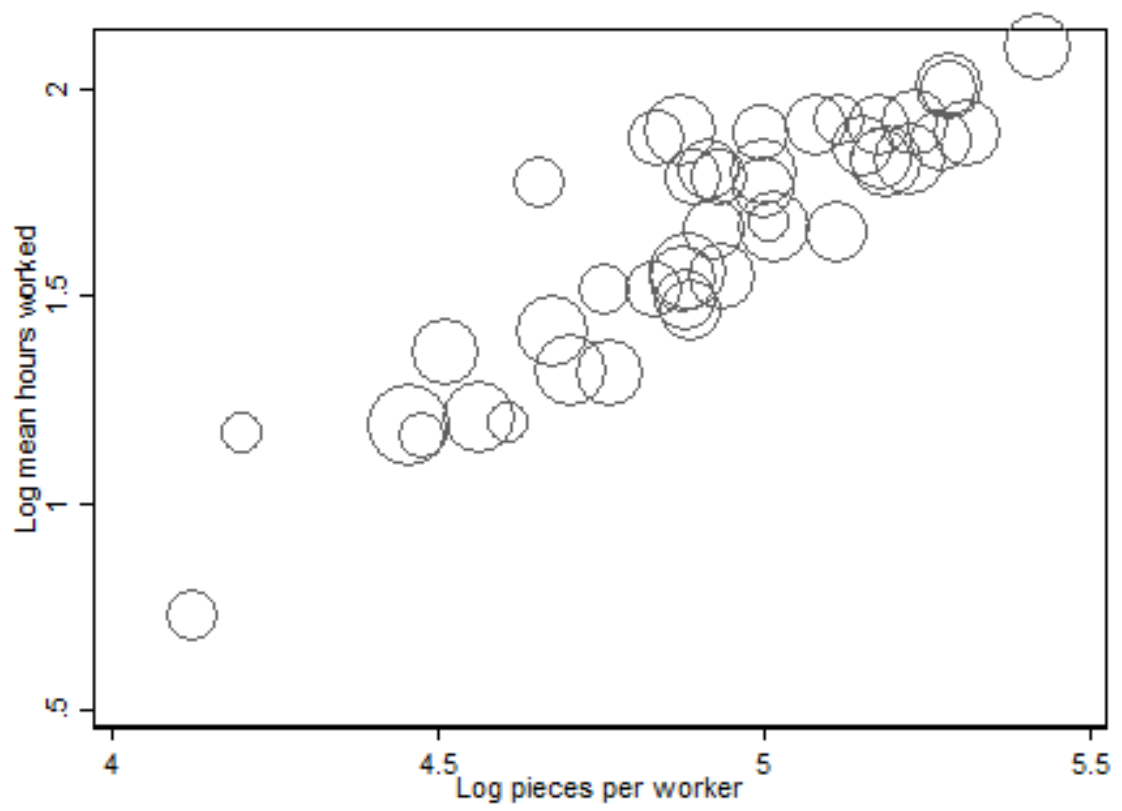

Based on data from the postprogram season (Year 3) and round variety. The pattern is similar when we use grape variety. This figure shows that workers' field hours worked (vertical axis) are strongly correlated with the field capacity or amount of crops available per worker (horizontal axis). Field capacity is proxied by the total pieces harvested at the day-field level, divided by the number of workers assigned to that day-field. The size of circles is proportionate to the number of workers represented in each case. A total of 43 day-field level observations are represented in the figure. 
Table 1: Worker and farm-level characteristics by pre and postprogram seasons

\begin{tabular}{|c|c|c|c|c|c|c|}
\hline & \multicolumn{4}{|c|}{ Pre } & \multirow{2}{*}{\multicolumn{2}{|c|}{$\frac{\text { Post }}{\text { Year } 3}$}} \\
\hline & \multicolumn{2}{|c|}{ Year 1} & \multicolumn{2}{|c|}{ Year 2} & & \\
\hline & Mean & Stdev & Mean & Stdev & Mean & Stdev \\
\hline & \multicolumn{6}{|c|}{ A. Worker-day-field-variety level } \\
\hline \multicolumn{7}{|c|}{ 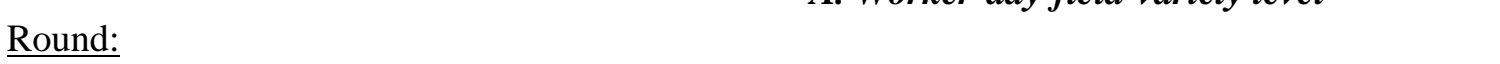 } \\
\hline 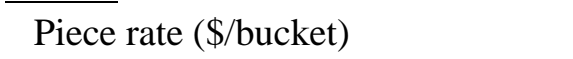 & 0.5 & & 0.5 & & 0.5 & \\
\hline Productivity (pieces/hour) & 21.47 & 6.53 & 24.07 & 8.51 & 26.48 & 6.82 \\
\hline Earnings per hour ( $\$$ /hour) & 10.74 & 3.27 & 12.04 & 4.26 & 13.24 & 3.41 \\
\hline Hours worked & 5.24 & 2.06 & 4.72 & 2.14 & 5.41 & 1.61 \\
\hline Obs & 10,444 & & 11,218 & & 7,874 & \\
\hline \multicolumn{7}{|l|}{ Grape: } \\
\hline Piece rate (\$/bucket) & 3.75 & & 3.75 & & 3.75 & \\
\hline Productivity (pieces/hour) & 2.64 & 0.90 & 2.74 & 1.03 & 2.49 & 1.04 \\
\hline Earnings per hour ( $\$$ /hour) & 9.90 & 3.38 & 10.28 & 3.87 & 9.35 & 3.90 \\
\hline Hours worked & 5.33 & 2.81 & 4.26 & 2.39 & 4.81 & 2.36 \\
\hline \multirow[t]{2}{*}{ Obs } & 10,606 & & 10,134 & & 8,659 & \\
\hline & \multicolumn{6}{|c|}{ B. Worker level } \\
\hline Share of field hours spent on Round & 0.47 & 0.34 & 0.55 & 0.27 & 0.47 & 0.26 \\
\hline Obs (number of unique workers) & 954 & & 1,187 & & 798 & \\
\hline \multicolumn{7}{|l|}{ Demograhics: } \\
\hline Age (years) & 27.98 & 7.54 & 29.56 & 8.51 & 29.60 & 8.20 \\
\hline Female & 0.11 & 0.32 & 0.12 & 0.32 & 0.12 & 0.32 \\
\hline Tenure (years) & 0.76 & 0.74 & 0.61 & 0.82 & 1.30 & 1.15 \\
\hline \multirow[t]{2}{*}{ Obs } & 766 & & 992 & & 671 & \\
\hline & \multicolumn{6}{|c|}{ C. Day-field-variety level } \\
\hline Workforce size: Round & 128.10 & 88.76 & 136.65 & 68.49 & 182.00 & 50.23 \\
\hline Obs & 81 & & 80 & & 43 & \\
\hline Workforce size: Grape & 113.87 & 86.01 & 105.89 & 77.44 & 146.59 & 76.62 \\
\hline Obs & 93 & & 95 & & 59 & \\
\hline
\end{tabular}

Notes: Sample includes workers who harvested either round or grape variety during any of the three harvesting seasons (Year 1, Year 2, and Year 3). The production data are trimmed at the top and bottom 2.5 percent of the year-variety specific productivity distribution. The PPP program is in place in Year 3 only. Piece rates paid by the ABC Farm remain constant throughout at $\$ 0.50 /$ bucket for Round and $\$ 3.75 /$ bucket for Grape, respectively, irrespective of the PPP program. Panel A displays summary statistics at the transaction (worker-day-field-variety) level. Panel B shows summary statistics at the worker level, including the number of unique workers in each season. In Panel B, share of field hours spent on round is obtained by dividing the worker's season total field hours spent on round by the worker' season total field hours spent on both varieties. Tenure is harvest year minus hire year. Panel C displays the day-field-variety level characteristics. 
Table 2: Penny Per Pound payment by workers

\begin{tabular}{lc}
\hline & Year 3 \\
\cline { 2 - 2 } Total earnings (\$) & 1449.92 \\
Total pieces (buckets) & $(890.08)$ \\
& 1902.84 \\
PPP bonus received $(\$)$ & $(1270.59)$ \\
& 114.24 \\
PPP bonus as share of total earnings & $(78.43)$ \\
& 0.08 \\
PPP bonus per piece (\$/bucket) & $(0.06)$ \\
\multicolumn{1}{c}{ Obs } & 0.07 \\
\end{tabular}

Notes: Based on worker-season level data from Year 3 and based on all varieties harvested at the ABC Farm. Table reports means with standard deviations in parentheses. 
Table 3: Worker productivity in pre versus postprogam periods

\begin{tabular}{|c|c|c|c|c|c|c|c|c|c|c|}
\hline & \multicolumn{10}{|c|}{ Dependent var: Log productivity (pieces/hour) } \\
\hline & \multicolumn{5}{|c|}{ Panel A: Round } & \multicolumn{5}{|c|}{ Panel B: Grape } \\
\hline & $(1)$ & (2) & (3) & (4) & (5) & (6) & (7) & $(8)$ & (9) & $(10)$ \\
\hline Post & $\begin{array}{c}0.181 * * * \\
(0.029)\end{array}$ & $\begin{array}{c}0.223 * * * \\
(0.031)\end{array}$ & $\begin{array}{c}0.244 * * * \\
(0.030)\end{array}$ & $\begin{array}{c}0.245^{* * * *} \\
(0.032)\end{array}$ & $\begin{array}{c}0.233 * * * \\
(0.040)\end{array}$ & $\begin{array}{l}-0.054 \\
(0.060)\end{array}$ & $\begin{array}{l}-0.048 \\
(0.049)\end{array}$ & $\begin{array}{l}-0.035 \\
(0.049)\end{array}$ & $\begin{array}{l}-0.096 \\
(0.058)\end{array}$ & $\begin{array}{l}-0.048 \\
(0.056)\end{array}$ \\
\hline Observations & 29,536 & 28,685 & 28,685 & 28,685 & 28,685 & 29,399 & 28,395 & 28,395 & 28,395 & 28,395 \\
\hline R-squared & 0.050 & 0.099 & 0.119 & 0.167 & 0.437 & 0.047 & 0.103 & 0.117 & 0.192 & 0.434 \\
\hline Field FE & Yes & Yes & Yes & Yes & Yes & Yes & Yes & Yes & Yes & Yes \\
\hline Climate controls & No & Yes & Yes & Yes & Yes & No & Yes & Yes & Yes & Yes \\
\hline Field lifecycle & No & No & Yes & Yes & Yes & No & No & Yes & Yes & Yes \\
\hline Supervisor FE & No & No & No & Yes & Yes & No & No & No & Yes & Yes \\
\hline Worker FE & No & No & No & No & Yes & No & No & No & No & Yes \\
\hline
\end{tabular}

Notes: Post indicates whether the day is in the post-PPP period (Year 3). Climate controls include a cubic of average temperature, precipitation, wind speed, and visibility, respectively. Field lifecycle includes a cubic of LC, where LC is computed as the number of calendar days the field has been picked for that variety at any moment in time divided by the total number of days the variety was picked in that field over the season. A total of 2,267 and 2,340 unique workers are represented in panel A and panel B, respectively. Robust standard errors clustered by harvesting days are in parentheses. $* * * \mathrm{p}<0.01, * * \mathrm{p}<0.05, * \mathrm{p}<0.1$. 
Table 4: DiD estimates of worker effort responses to the PPP program

\begin{tabular}{|c|c|c|c|c|c|}
\hline & \multicolumn{5}{|c|}{ Dependent var: Log productivity (pieces/hour) } \\
\hline & $(1)$ & $(2)$ & (3) & $(4)$ & (5) \\
\hline Post x Round & $\begin{array}{c}0.277 * * * \\
(0.067)\end{array}$ & $\begin{array}{c}0.392 * * * \\
(0.069)\end{array}$ & $\begin{array}{c}0.397 * * * \\
(0.075)\end{array}$ & $\begin{array}{c}0.399 * * * \\
(0.078)\end{array}$ & $\begin{array}{c}0.392 * * * \\
(0.085)\end{array}$ \\
\hline Post & $\begin{array}{l}-0.071 \\
(0.059)\end{array}$ & & & & \\
\hline Round & $\begin{array}{c}2.131 * * * \\
(0.028)\end{array}$ & $\begin{array}{c}2.112 * * * \\
(0.032)\end{array}$ & $\begin{array}{c}2.107 * * * \\
(0.037)\end{array}$ & $\begin{array}{c}2.135 * * * \\
(0.039)\end{array}$ & $\begin{array}{c}2.139 * * * \\
(0.042)\end{array}$ \\
\hline Observations & 58,935 & 58,935 & 58,935 & 58,935 & 58,935 \\
\hline R-squared & 0.905 & 0.925 & 0.925 & 0.928 & 0.948 \\
\hline Field FE & Yes & Yes & Yes & Yes & Yes \\
\hline Day FE & No & Yes & Yes & Yes & Yes \\
\hline Field lifecycle & No & No & Yes & Yes & Yes \\
\hline Supervisor FE & No & No & No & Yes & Yes \\
\hline Worker FE & No & No & No & $\mathrm{No}$ & Yes \\
\hline
\end{tabular}

Notes: Post indicates whether the day is in the post-PPP period (Year 3). Round indicates whether the variety picked is Round (as opposed to Grape) tomatoes. Climate controls are subsumed in the day FE. Field lifecycle includes a cubic of LC, where LC is computed as the number of calendar days the field has been picked for that variety at any moment in time divided by the total number of days the variety was picked in that field over the season. A total of 2,528 unique workers are represented in the table. Robust standard errors clustered by harvesting days are in parentheses. $* * * \mathrm{p}<0.01, * * \mathrm{p}<0.05, * \mathrm{p}<0.1$. 
Table 5: DiD estimates allowing for variety-specific effects of climatic conditions

\begin{tabular}{|c|c|c|c|c|c|c|}
\hline & \multicolumn{6}{|c|}{ Dependent var: Log productivity (pieces/hour) } \\
\hline & $(1)$ & $(2)$ & $(3)$ & $(4)$ & $(5)$ & $(6)$ \\
\hline Post x Round & $\begin{array}{c}0.392 * * * \\
(0.082)\end{array}$ & $\begin{array}{c}0.398 * * * \\
(0.084)\end{array}$ & $\begin{array}{c}0.399 * * * \\
(0.082)\end{array}$ & $\begin{array}{c}0.392 * * * \\
(0.083)\end{array}$ & $\begin{array}{c}0.408 * * * \\
(0.079)\end{array}$ & $\begin{array}{c}0.419 * * * \\
(0.079)\end{array}$ \\
\hline Observations & 57,080 & 57,080 & 57,080 & 57,080 & 57,080 & 57,080 \\
\hline R-squared & 0.928 & 0.928 & 0.928 & 0.928 & 0.928 & 0.928 \\
\hline Climate $\mathrm{x}$ Round & None & Temperature & Rainfall & Visibility & Windspeed & All \\
\hline $\begin{array}{l}\text { Notes: Sample is re } \\
\text { the day is in the p } \\
\text { opposed to Grape) } \\
\text { supervisor FE (sam } \\
\text { climate conditions } \\
\text { Robust standard er }\end{array}$ & $\begin{array}{l}\text { ted to ob: } \\
\text { PP perioc } \\
\text { toes. All } \\
\text { column } 4 \\
\text { Round v } \\
\text { lustered }\end{array}$ & $\begin{array}{l}\text { rvations with } \mathrm{r} \\
\text { (Year 3). Rour } \\
\text { egressions incl } \\
\text { f Table 4). Cli } \\
\text { iety. A total o } \\
\text { harvesting day }\end{array}$ & $\begin{array}{l}\text { n-missing } \\
\text { indicates } \\
\text { le Round } F \\
\text { ate } x \text { Roun } \\
2,520 \text { uniqu } \\
\text { are in pare }\end{array}$ & $\begin{array}{l}\text { mate varial } \\
\text { eether the } \\
\text { field FE, } \\
\text { controls for } \\
\text { workers a }\end{array}$ & $\begin{array}{l}\text { es. Post indic } \\
\text { riety picked } \\
\text { y FE, field li } \\
\text { he interaction } \\
\text { represented } \\
<0.01, * * p<0\end{array}$ & $\begin{array}{l}\text { Round (as } \\
\text { cycle, and } \\
\text { f observed } \\
\text { the table } \\
5, * \mathrm{p}<0.1\end{array}$ \\
\hline
\end{tabular}


Table 6: Effects of placebo treatment

\begin{tabular}{|c|c|c|c|c|c|c|c|c|}
\hline \multirow[b]{2}{*}{ Sample: } & \multicolumn{8}{|c|}{ Dependent var: Log productivity (pieces/hour) } \\
\hline & $\begin{array}{c}\text { All years } \\
\text { (1) }\end{array}$ & $\begin{array}{c}1 \& 2 \\
(2)\end{array}$ & $\begin{array}{c}1 \& 3 \\
(3)\end{array}$ & $\begin{array}{c}2 \& 3 \\
\text { (4) }\end{array}$ & $\begin{array}{c}\text { All years } \\
(5)\end{array}$ & $\begin{array}{c}1 \& 2 \\
(6)\end{array}$ & $\begin{array}{c}1 \& 3 \\
\text { ( } 7 \text { ) }\end{array}$ & $\begin{array}{c}2 \& 3 \\
(8) \\
\end{array}$ \\
\hline Year 2 x Round & $\begin{array}{c}0.014 \\
(0.071)\end{array}$ & $\begin{array}{c}0.069 \\
(0.055)\end{array}$ & & & $\begin{array}{c}0.006 \\
(0.075)\end{array}$ & $\begin{array}{c}0.033 \\
(0.059)\end{array}$ & & \\
\hline Year 3 x Round & $\begin{array}{c}0.406^{* * *} \\
(0.079)\end{array}$ & & $\begin{array}{c}0.310 * * * \\
(0.067)\end{array}$ & $\begin{array}{c}0.241 * * * \\
(0.078)\end{array}$ & $\begin{array}{c}0.395 * * * \\
(0.085)\end{array}$ & & $\begin{array}{c}0.283 * * * \\
(0.077)\end{array}$ & $\begin{array}{c}0.254 * * * * \\
(0.086)\end{array}$ \\
\hline Observations & 58,935 & 42,402 & 37,583 & 37,885 & 58,935 & 42,402 & 37,583 & 37,885 \\
\hline No. unique workers & 2,528 & 1,987 & 1,660 & 1,759 & 2,528 & 1,987 & 1,660 & 1,759 \\
\hline R-squared & 0.928 & 0.896 & 0.916 & 0.902 & 0.948 & 0.925 & 0.939 & 0.929 \\
\hline Worker FE & No & No & No & No & Yes & Yes & Yes & Yes \\
\hline
\end{tabular}

Notes: This table shows that the disproportionate productivity increase in the round variety is specific to Year 3, the year of the PPP program. Year 2 and Year 3 indicate whether the observation is in the respective calendar years. Round indicates whether the variety picked is Round (as opposed to Grape) tomatoes. All regressions include Round FE, field FE, day FE, field life cycle, and supervisor FE (same as column 4 of Table 4). Columns 5 through 8 additionally include worker FE. Robust standard errors clustered by harvesting days are in parentheses. *** $\mathrm{p}<0.01,{ }^{*} \mathrm{p}<0.05,{ }^{*} \mathrm{p}<0.1$. 
Table 7: Potential effects of the PPP program on the workforce size in the field

\begin{tabular}{|c|c|c|c|c|c|c|c|c|}
\hline \multirow{3}{*}{ Mean of D.V.: } & \multicolumn{8}{|c|}{ Dependent var: } \\
\hline & \multicolumn{4}{|c|}{$\begin{array}{c}\log \text { (size of workforce) } \\
4.56\end{array}$} & \multicolumn{4}{|c|}{$\begin{array}{c}\text { Size of workforce } \\
130\end{array}$} \\
\hline & (1) & (2) & (3) & (4) & (5) & (6) & (7) & $(8)$ \\
\hline Post $\mathrm{x}$ Round & $\begin{array}{c}0.211 \\
(0.217)\end{array}$ & $\begin{array}{c}0.283 \\
(0.222)\end{array}$ & $\begin{array}{c}0.279 \\
(0.220)\end{array}$ & $\begin{array}{c}0.309 \\
(0.237)\end{array}$ & $\begin{array}{c}10.232 \\
(18.972)\end{array}$ & $\begin{array}{c}19.757 \\
(19.034)\end{array}$ & $\begin{array}{c}17.031 \\
(20.090)\end{array}$ & $\begin{array}{c}25.612 \\
(16.894)\end{array}$ \\
\hline Observations & 451 & 451 & 451 & 443 & 451 & 451 & 451 & 443 \\
\hline R-squared & 0.590 & 0.621 & 0.713 & 0.714 & 0.533 & 0.597 & 0.670 & 0.670 \\
\hline Field lifecycle & No & Yes & Yes & Yes & No & Yes & Yes & Yes \\
\hline Supervisor FE & No & No & Yes & Yes & No & No & Yes & Yes \\
\hline Climate x Round & No & No & No & Yes & No & No & No & Yes \\
\hline
\end{tabular}

Notes: This table shows day-field-variety level regressions. Size of workforce is the number of workers picking the same variety in the same field on the same day. Post indicates whether the day is in the post-PPP period (Year 3). Round indicates whether the variety picked is Round (as opposed to Grape) tomatoes. All regressions include Round FE, field FE and day FE. Climate controls are subsumed in the day FE. Field lifecycle includes a cubic of LC, where LC is computed as the number of calendar days the field has been picked for that variety at any moment in time divided by the total number of days the variety was picked in that field over the season. Columns 4 and 8 allow for variety specific effects of climate variables, where the climate variables includes average temperature, precipitation, wind speed, and visibility. Robust standard errors clustered by harvesting days are in parentheses. $* * * \mathrm{p}<0.01, * * \mathrm{p}<0.05, * \mathrm{p}<0.1$. 
Table 8: Hours worked in relation to field capacity and the PPP program

\begin{tabular}{lcccc}
\hline & \multicolumn{4}{c}{ Log (hours worked) } \\
\cline { 2 - 5 } & $(1)$ & $(2)$ & $(3)$ & $(4)$ \\
\cline { 2 - 5 } Post x Round & & & $-0.253^{* * *}$ & $-0.255^{* * *}$ \\
& & & $(0.0621)$ & $(0.0614)$ \\
Log (field capacity) x Round & & $-0.119^{*}$ & -0.0926 & -0.0821 \\
& & $(0.0656)$ & $(0.0605)$ & $(0.0629)$ \\
Log (field capacity) & $0.679 * * *$ & $0.733 * * *$ & $0.753 * * *$ & $0.757 * * *$ \\
& $(0.0329)$ & $(0.0472)$ & $(0.0445)$ & $(0.0440)$ \\
Observations & & & & \\
R-squared & 58,935 & 58,935 & 58,935 & 58,935 \\
Workforce size & 0.430 & 0.431 & 0.436 & 0.437 \\
\hline
\end{tabular}

Notes: This table examines the relationship between the field hours that each worker spent on each dayfield-variety and the field capacity or amount of crops available per worker on that day-field-variety. Field capacity is proxied by the total pieces harvested on the day-field-variety level, divided by the number of worked assigned to that day-field-variety. All regressions include Round FE, field FE, day FE, field lifecycle, and supervisor FE (same as column 4 of Table 4). Column 4 additionally controls for $\log$ of workforce size in that day-field-variety. A total of 2,528 unique workers are represented in this table. Robust standard errors clustered by harvesting days are in parentheses. $* * * p<0.01, * * p<0.05$, $* \mathrm{p}<0.1$. 